Final submitted and accepted version

Reichenberger, I. (2017). Why the host community just isn't enough - processes and impacts of backpacker social interactions. Tourist Studies, 17(3), 263-282. 


\section{Why the host community just isn't enough - processes and impacts of backpacker social interactions}

This research uses an extended social situation analysis to examine how social interactions of backpackers in New Zealand are manifested, how they can contribute to the visitor experience, to common travel motivations such as self-development and cultural exploration, and how they compare to and influence contacts with the host community. Results from 37 in-depth interviews indicate that backpacker interactions underlie strict rules and are based on a shared understanding of how they are to proceed in terms of conversation topics and personal elements. Certain settings and a positive relationship between interaction participants contribute to longer and more personal social interactions. These in turn are required for emotional well-being, which is why fellow backpackers often replace friends and family as a social support system. Due to the national diversity of backpacker travellers, these interactions also provide exposure to different cultures as well as opportunity for self-development. Contacts with the host community however have been reported to be more difficult to establish and were found to be less beneficial for backpackers who have to rely heavily on interaction partners who are social, desire to spend longer amounts of time and are willing to proceed to a more familiar level faster than non-travellers.

Keywords: backpackers; social interaction; visitor experience; social situation analysis; New Zealand 


\section{Introduction}

Although tourism is often considered 'an individualistic practice, sometimes solitary, even self-centred, it is frequently not so' (Crouch, Aronsson, \& Wahlstrom, 2004, p. 284). Even if not with, tourism often happens alongside other people, which results in constant encounters, and even their simple presence provides people with the ability to influence others, and can significantly alter an experience (Crouch et al., 2004). This is especially applicable to the travel form of backpacking. While the backpacker culture has evolved and changed over these past two decades, most notably with the emergence of flashpackers as older and more affluent travellers (Hannam \& Diekmann, 2010; Jarvis \& Peel, 2010; Paris, 2012), the importance of the social aspect for this form of travelling and the emphasis on interactions with both fellow travellers and host communities continues to remain an integral part of this travel style (e.g. Binder, 2004; Murphy, 2001; O’Reilly, 2006; Paris, 2012). Nevertheless, it is still unknown how exactly the social motive contributes to the experience of these individuals. In addition, discrepancies have been found between the estimated and actual contact of backpacker travellers with the host community (Wilson \& Richards, 2008), highlighting how little is known about what is supposedly a crucial element of the backpacker experience.

This study seeks to address these gaps by examining how and why backpacker travellers in New Zealand - long considered one of the 'traditional' destinations for backpackers (Hannam \& Diekmann, 2010) - interact with each other and how this compares to their interactions with members of the host community. Furthermore, it aims to examine the impact of these social interactions on the visitor experience - how do backpackerbackpacker interactions contribute to both the specific situations within which they occur and to the overall trip, and in what relation do they stand to the overarching common travel motivations of self-development and cultural explorations? By achieving greater insight in 
the reasons for and underlying complexities of what appears to be a - if not 'the' - core component of backpacker travel, a deeper understanding of this segment can be achieved. In drawing out the reciprocities between travel motivations and their subsequent manifestations, more light will be shed on backpackers' needs and sought benefits and the circumstances of their potential fulfilment. Both scholars and practitioners alike can benefit from an increased transparency that contributes to our understanding of this visitor type. Results of this study will challenge previous interpretations of how travel motivations such as interests in foreign cultures and sociability are fulfilled through social behaviour, and will simultaneously illustrate how social encounters can influence the perception of tourism products, attractions and services, thus offering a new perspective on the assigned importance of the social element in the context of visitor satisfaction.

\section{The social context of backpacking}

Backpackers are commonly defined as travellers 'who exhibit a preference for budget accommodation; an emphasis on meeting other people (locals and travelers); an independently organized and flexible travel schedule; longer rather than brief holidays; and an emphasis on informal and participatory recreation activities' (Loker-Murphy \& Pearce, 1995, p. 831). Frequently on a gap year marking the transition between secondary and tertiary education or between student and full-time employment, backpacking is often regarded as a rite of passage in Western cultures (Huxley, 2004; Paris \& Teye, 2010), allowing individuals the search for experiences that contribute to the development, production and transformation of self (Neumann 1992; Tucker, 2005; Whiting and Whiting, 2004). Self-identity and its relation to travel and the narration of travel experiences has already been the subject of research (e.g. Noy, 2004; Tucker, 2005), identifying the relevance of constructing one's identity through storytelling, self-presentation and self-reflection. Self-development and 
learning about other cultures are thus frequent and recurring motivations associated with this travel style, inextricably connected to a strong desire for sociability and meeting other people (e.g. Newlands, 2004; Niggel \& Benson, 2008; Paris \& Teye, 2010; Richards \& Wilson, 2004; Tucker, 2005). While contacts with other travellers are consistently part of the reasoning behind choosing this travel style, particular importance is assigned to encounters that allow backpackers to experience the respective local culture (Huxley, 2004; Scheyvens, 2002).

However, backpackers have been found to exhibit only minimal genuine exchanges with foreign cultures, and appear to fulfil the desire for broadening cultural horizons more through the role of an observer than an active participant (Huxley, 2004). In addition, the development of so-called backpacker enclaves may further contribute to a lack of interaction with the host community, thus standing in contrast to the common assumption that backpackers aim to travel outside the tourist bubble (Huxley, 2004). As backpackers often follow similar routes throughout a country, they frequently find themselves in - or seek out meeting places for Western travellers (Howard, 2007; Huxley, 2004; Wilson \& Richards, 2008). Indeed, there is now a degree of institutionalisation of backpacker tourism through increased organization, similar travel paths and targeted product development (Ateljevic \& Doorne, 2004; Vance, 2004) that contributes to such enclaves and thus often to fewer interactions with the host community (Bushell \& Anderson, 2010; Howard, 2007; Wilson, Richards, \& MacDonnell, 2008) by functioning as a barrier to authentic local culture (Huxley, 2004). The gap between original motivations and practice, the difficulty of obtaining these desired cultural experiences, is partially filled by the surrogate cultural experiences available in such enclaves through this existing subculture (Wilson and Richards, 2008), thus raising the question what role social interactions play within the individual travel experience and for their underlying motivations of self-development and cultural exploration. 
Although it may subsequently be assumed that interactions with other tourists especially other backpackers - constitute a large part of the social aspect of backpacking, little research has actually been done to further examine this issue and explore the role that social encounters play for backpackers in the context of increasingly institutionalized tourism infrastructure. Recommendations and word of mouth have been identified as an important reason why backpackers interact with each other (Murphy, 2001), and it has been found that backpackers in Asian countries frequently look for travel companions for safety and security reasons (Huxley, 2004). In addition, narrating one's experiences to other travellers contributes to the motive of self-development as it aids the construction of self and identity; the role of the other as opposed to the self however has not been sufficiently explored. Considering the strength of the social motive in the backpacker experience, further research is required to address this aspect in more detail to understand not only the extent of its relevance but also the ways in which social interactions can impact, change or even produce individual experiences and their interconnectedness with the commonly overarching goals that underlie this particular travel form.

It is, after all, acknowledged that contacts with other visitors do play a role within their individual visitor experiences (e.g. Mossberg, 2007; Pearce, 2005a, 2005b; Walls \& Wang, 2011). Several studies have discovered connections between the social components of a tourism related activity or experience and the subsequent satisfaction with it (e.g. Grove \& Fisk, 1997; Huang \& Hsu, 2010; Levy \& Getz, 2012). Although the visitor experience is a widely researched construct that has received much attention (see Ryan, 2010 for an overview), its social aspect in particular has been consistently neglected. Only one study has been found to specifically focus on backpacker social interactions (Murphy, 2001), but this did not take into account the personal meaning of these interactions for respondents and its contribution to their overall travel experience. Research examining consumer-to-consumer 
interactions in tourism settings has also not considered the motivations behind, contents, processes and impacts of social interactions (e.g. Grove \& Fisk, 1997; Harris \& Baron, 2004; Heimtun, 2011; Huang \& Hsu, 2010; Levy \& Getz, 2012; Wu, 2007) and therefore cannot contribute to new insight into the place of social interactions within backpacking. In order to examine the role that social interactions play for the backpacker travel experience, it is thus necessary to first shed light on their processes to gain more detailed insight into how this phenomenon is manifested. Only by knowing what is happening during backpackerbackpacker interactions can their resulting effects be fully understood, and only then can current research gaps be addressed. These include the ways in which interactions contribute to self-development, the reasons behind low host community contacts, and the ensuing perceived lack of authentic cultural exploration.

\section{Analysing social interactions}

Since this exploratory research aims to not only understand the impacts but also the processes of backpacker social interactions, a two-fold approach was required. At the core of this approach stand Argyle, Furnham and Graham's (1981) features of social situations as the circumstances of social interactions. This social psychological approach aims to deconstruct the complexity of social encounters and to provide greater insight into the ways in which coactions of individuals are determined by identifying the structure and elements of social interactions and their connections. A social situation is defined as "the sum of features of the behaviour system, for the duration of a social encounter" (Argyle et al., 1981, p. 3) - these social encounters in turn are said to possess nine distinct yet interconnected features, whose combination structures and determines social situations and the social interactions occurring within. They include the environmental setting, social roles, goals, the repertoire of elements appropriate for the situation, sequences of behaviour, rules, concepts and cognitive structures 
as shared understandings, as well as language and speech. Originally only concerned with generalisable reciprocities and connections, the social situation features alone do not yet provide in-depth insight into the reality of individual social situations. However, they have since been applied to examine the structures and processes of social interactions within tourism settings (Murphy, 2001; Pearce, 1984, 1990), and thus provide a tested framework to examine social encounters in particular settings and contexts. For this study, the features of social situations are used to shed light on the details of backpacker social interactions.

These features, however, are limited by their focus on the abstract phenomenon of a social situation itself, and as such do not provide sufficient insight for the wider scope of this research. The impact that individual interaction participants and their personalities can have on an interaction have been neglected, which is why an expansion of this framework is required to address the social aspect of backpacking in more comprehensive detail. The original positivist focus concerned only with processes and symptoms (Gough, McFadden, \& McDonald, 2013) needs to be expanded to include post-structuralist perspectives to acknowledge and understand not only the social interactions but also the production process itself and the role that producers play by creating a reality instead of only participating. For the purpose of this study, the features of social situations have thus been extended to include personality type and the relationship between interaction partners as shown in Table 1.

\section{Table 1}

Due to the lack of research on the social aspect of tourism in general and visitorvisitor interactions in particular, a qualitative approach in form of semi-structured personal in-depth interviews was chosen. This allowed for examining the social situation features to determine not only the structure and process of backpacker social interactions but also the 
individual roles of interaction participants, as well as additional information on the perception, processes and impacts of interactions and the relevance of host community contacts.

\section{Methodology}

As part of a larger and more comprehensive study, thirty-seven interviews with backpackers were conducted in visitor information centres in Rotorua and Wellington, New Zealand. The locations provide a wide variety of activities and situations in which backpacker interactions with other travellers can occur, and choosing a neutral interview location excluded a potential bias resulting from travellers choosing different hostels based on location, reputation, size, price or brand. As well as elaborating on the previously outlined more general factors relating to the social aspect of their travels, respondents were also asked to describe two specific social interactions with other visitors they had had during the current or previous day in detail to examine the manifestation of Argyle et al.'s situational features (1981). Interactions with non-visitors were excluded, as the exploratory qualitative nature of this research did not allow additional interactions with locals, tourism industry employees or other individuals to be considered in the depth that would be required to provide sufficient insight into the phenomenon.

Interviews lasted between 30 and 60 minutes, were recorded and later transcribed and analysed using qualitative data analysis software (NVivo 9), using a targeted data analysis adherent to the framework as well as an analysis stage based on unrelated emerging themes. The information contained within the transcripts could be divided into two parts - one part referred to the social aspect of travelling in more general terms and the second part elaborated on the two specific social interactions with other visitors. This was to examine both patterns 
of interactions and personal experiences, and would enable the emergence of interdependencies, interrelationships and patterns within particular social interactions while still maintaining the flexibility to incorporate individual experiences and personal perceptions required to identify the relevance of these interactions for travel motivation and experience.

Respondents were identified as backpackers based on choosing more inexpensive youth hostels as their main choice of accommodation in combination with public transport, and most importantly explicitly perceiving and describing themselves as backpackers, thus self-identifying with this particular category. Those that did not fit these criteria were analysed separately and are not part of the sample included in this paper. The characteristics found in this sample correspond both to Tourism New Zealand's youth traveller segment (Tourism New Zealand, 2013a, 2013b) and Loker-Murphy and Pearce's (1995) widely accepted definition and are displayed in Table 2 below.

Table 2

This paper will now examine the characteristics and processes of respondents' social interactions with other visitors according to Argyle et al.'s (1981) situational features and their two additions of personality type and interaction partner relationship. Based on this, the impact of social interactions on the backpacker travel experience and their contribution to common backpacker travel motivations such as self-development and cultural exploration will then be discussed, before further exploring how they compare to contacts with the host community. Verbatim quotes of respondents representing commonly reported occurrences, experiences and opinions will be used throughout to let the voice of travellers be heard. 


\section{Situational features}

\section{Roles}

The most frequently referred to role attached to backpacker travellers was the expected sociability and openness towards other visitors which strongly contributed to the ease with which interactions occurred. This is partly based on the common assumption that social contacts are perceived positively by this type of traveller, and partly on the fluidity of travel and the subsequent lack of time to establish contacts.

'As a backpacker, people expect you to be social, you know? It's this thing, the talking to others, meeting others, I mean everything in hostels is made, designed for this, and it makes it hard to be on your own if you want to be.'

Male, UK

However, although respondents sometimes emphasized the need for personal time, they also consciously attempted to eliminate solitude. The majority were single long-term travellers and often referred to this status to highlight the possibility of spending several days or even weeks with other visitors they have met during their holiday. This particular role in turn resulted in backpackers often selecting their potential interaction partners by certain criteria. While the current proximity to each other played an overarching and highly relevant role in interaction partner selection, the visual appearance of other visitors was also frequently mentioned by respondents to pre-determine potential commonalities. 


\section{Environmental Setting}

Youth hostels as the preferred type of accommodation have previously been shown to be an environment that encourages social interactions, due to its atmosphere, reputation and physical layout with shared spaces (Murphy, 2001; O'Regan, 2010). In addition, this particular interaction setting meant that interactions within were frequently not limited by time constraints.

'In the hostels, the people you share the room with, or in the kitchen. Always in the kitchen, classic example, you have so much time in the evenings.' Male, Germany

While Argyle et al. (1981) emphasized especially the importance of the physical aspects of the environment and its potential for interruptions, for backpackers the location determined their own personal circumstances. The available time and lack of other distractions allowed them to make use of the social atmosphere and proximity-encouraging layout, therefore leading to frequent interactions with other backpackers and comparatively fewer interactions with both locals and other visitors that do not enter these particular settings during their holidays. While this is neither unexpected nor previously unknown information, the environmental setting has far reaching implications for the process and also impact of social interactions that can occur and are encouraged within.

\section{Goals}

The specific reasons why backpackers interacted with other visitors were partly determined through the environmental settings within which these interactions occurred as well as the 
roles attached to backpacking; however the importance they assigned to meeting others throughout their holiday played an overarching role. Nearly all respondents strongly emphasized the personal importance of contacts with other visitors and the mostly emotional and intrinsic rewards such as fun and entertainment they hope to gain from them.

While it has been found that backpackers rely heavily on word of mouth from other visitors during their travels (Murphy, 2001), respondents reported to seldom interact simply because of an extrinsic desire for information. Although information exchange was an important component of their interactions as illustrated in the following section, the intrinsic pleasure gained by meeting new people was often reported to be of far higher relevance than the need for recommendations.

'Because it's fun. Sitting alone all day is boring after a while, you need company, especially when you're travelling for longer. That's really why I like to meet others. You get a lot of information and recommendations too, but mostly it's fun!' Female, Germany

\section{Repertoire and sequences of behaviour}

Accommodation settings have been found to encourage longer interactions that are desired by backpackers due to their frequent status as single travellers. While these social interactions were often reported to last for several hours, some continued for days or even weeks. But regardless of duration, virtually all respondents described a routine-like initial conversation topic sequence with a restricted repertoire of behaviour that they reported to be applicable to nearly all interactions they have had with other visitors during their holiday. Interactions with other travellers always began with an initial greeting, an enquiry about the interaction partner's country of origin and an exchange about the respective travel patterns. These initial 
questions were often referred to as 'backpacker talk' or 'ice-breakers' to establish a first level of familiarity that would later allow for the introduction of further topics.

While this pattern has also been found applicable to other participants of the larger study that were not travelling as backpackers, the advancement to introduce more private details was a phenomenon nearly exclusively observed in the backpacker segment and was also observed by Riley (1988), who emphasized the unusually quick establishment of friendships. Most commonly, interactions then included information about occupation, reasons for travelling or family background. If time allowed, many interactions then went beyond these still superficial personal topics and included personal preferences or more private matters, with topics becoming more personal the longer the interaction lasted. Interactions continuing for several days would then begin to mirror those that might be had with closer friends at home, as the interaction was perceived to have progressed to the level of a personal relationship.

'I'd say the usual first question is where are you from, how long do you stay, what have you done, when do you leave. It's always the same really, but you need to get that out of the way first, you have to talk about this. And then, if there's some interest, it's about, well a bit more about the people, what they do at home, and why they're here.'

Female, Germany

\section{Rules, concepts and cognitive structures}

An understanding of the rules determining behavioural elements and their sequence as outlined above seemed to have been shared by all respondents. Although no interactions were 
reported that included topics or behaviour that were felt not to be appropriate, the need for an initial personal distance before proceeding to a more familiar level was emphasized.

'If it's somehow getting so personal soon, somehow I don't like that. You should get to know each other better before you tell someone quite private things.' Female, Germany

A consistently negative attitude of interaction participants towards either specific situations or the overall holiday was also perceived as undesirable. In these cases, the respective interaction was often terminated by respondents if the situation allowed them to do so. In summary, social interactions between backpackers display very clear and universal rules as to how a certain level of familiarity is to be achieved and what steps must be undertaken in order to be able to proceed to a more personal level if so desired. In addition, both a positive attitude and mutual consideration are regarded as rules that should be adhered to in order to participate in a positive social interaction experience.

While these patterns cannot expected to be applicable only to backpackers, the speed with which the introduction of more private topics becomes acceptable and even desired behaviour certainly is - this is based on the unique combination of desiring more profound and personal interactions and the little amount of time available to establish such contacts.

\section{Language and speech}

While language and speech as factors influencing social situations first and foremost referred to how things were said within conversations and what vocabulary was used (Argyle et al., 1981), it emerged in a different context throughout this research and was inextricably linked with nationality. Nationality was a factor repeatedly mentioned both as encouraging and 
discouraging social interactions. Respondents with a longer travel duration reported to often enter into interactions with other visitors when realizing that they were speaking the same language or were from the same country, whereas those with a shorter length of stay or still in the early stages of travelling sometimes actively avoided travellers from their home country. Especially interesting is thus the different value placed on interactions with travellers from one's own country. With increasing travel duration, the overarching desire for new experiences is, on occasion, replaced by a growing need for familiarity and ease.

\section{Beyond situational features}

Argyle et al.'s (1981) original features of social situations provided a useful framework to analyse the circumstances, processes and contents of social interactions of backpackers with other travellers. Preferred environmental interaction settings were identified, due to a combination of travel style and the opportunities they provide for the fulfilment of mostly intrinsic goals. The social role attached to backpacker travel as well as their status as often single long-term travellers led to often very long interactions, when selected interaction partners became travel partners. Quite specific sequences of behaviour were found to be applicable to all respondents and their interactions, clearly identifying what behavioural repertoire is considered appropriate at what stage of the interaction process. These also functioned as shared rules and structures, as a disregard of these often led to an early interaction termination. However, it still remains unknown why certain interactions proceed to a more personal and emotional level whereas others are regarded as 'backpacker talk' and do not go beyond travel related exchanges.

The following sections will now address the additional personality-related factors to present a more comprehensive and in-depth picture of backpacker social interactions which 
will then serve as the foundation for analysing their impacts and contributions to the backpacker experience.

\section{Personality type}

The personal attitude towards social interactions with other travellers and the importance placed upon them often aligned with the sociability of respondents. Those that described themselves as more extroverted personalities during this holiday frequently emphasized the importance of social interactions with other visitors as well as the high number of interactions that had occurred so far. More introverted travellers on the other hand sometimes found the social atmosphere of popular youth hostels too busy for their taste and preferred to seek out environments where they found it easier to reduce the number of social encounters that often come with backpacking.

'I don't like hostels where a lot of backpackers and a lot of, ah, Kiwi or Magic bus travellers, because it's so busy and all of them are so stressed or drunk and, so I prefer smaller hostels with special, ahm, atmosphere. You can be on your own there, I'm not so outgoing, and I prefer this.'

Female, Germany

While interactions with other travellers are commonly agreed to be a core aspect of the visitor experience of this often extroverted visitor type, the demands that come with these continuous interactions also sometimes lead to periods when a more introverted approach is taken and periods with less sociability are welcomed. 
'Sometimes it's nice to just have a few days on your own. Not always, yeah, I really thought I wouldn't be, because I really like to talk to people, but (...) at home, you have that already, you're alone at home, and here you have people talking to you all day.'

Female, Netherlands

\section{Interaction partner relationship}

So far, this paper has identified a number of factors that contribute to and determine the processes of backpacker interactions; however a mutual likeability is an underlying basic requirement for any interaction whose process is intrinsically motivated. Without a positive interaction partner relationship, there is no motivation to continue further with an interaction. This likeability or, as it was often called, a connection, frequently depends upon commonalities between interaction partners. These can be limited to the commonality of being travellers in the same country, but more often extend to a personal level. The lack of commonalities on the other hand can negatively impact the interaction process by providing no common grounds on which a conversation can be based.

'The difference is that I'm a little bit older, because a lot of people travelling alone, they, ah, are in a life changing situation, so, I'm not so interested in these discussions or conversations, we don't have much in common.'

Female, Germany

Although commonalities often contribute to a more personal interaction, a lack of commonalities can, under certain circumstances, function in much the same way when a new interest is awakened. 
'I always find, when people talk about themselves, I always ask when I'm interested, for example they do something completely different, and say something interesting about something that I would never do like this, then I like to ask more.'

Male, Germany

\section{Impacts on the backpacker experience}

Based upon duration, conversation topics and interaction partner relationship, interactions with other travellers were reported to impact the backpacker experience in a variety of ways and on two different levels. Here, situational impacts refer to the impact of these interactions on the current situation, while the sum of all interactions experienced throughout the holiday contributes to impacts on the full backpacker experience had within New Zealand.

\section{Situational impacts}

While very short interactions that did not go beyond the usual backpacker talk were sometimes reported to have no particular impact on the current situation, those that included some personal elements consistently had, and were reported to do so in three different ways. Firstly, all interactions contributed a fun and entertaining element, enabled through the consistent informality of backpacker interactions:

'Fun, yeah, it was just fun. Cracking some jokes, having a beer after a long day, it's been awesome.'

Male, UK 
In addition, backpacker interactions often contributed positively to the current mood and a sense of emotional fulfilment, including the effects of these interactions on both general and current wellbeing for long-term travellers.

'It was just nice to be social, to talk to someone. I felt better, happy, and, I mean not talking to anyone for a while, it just makes me miserable.'

Female, USA

The positive impact of a shared and thus often enhanced experience was the third way in which backpacker interactions impacted the current situation. Respondents often highlighted that their enjoyment was increased by sharing an experience with others, as well as being enhanced by the opportunity to see how others experienced the same situation.

'You're sharing that experience, New Zealand is new for everybody, so it's an excitement for everyone to see how others see it, others from different places and countries.'

Female, Canada

The longer interactions lasted, the more personal they became, and the better the interaction partner relationship was perceived, the more likely were interactions to have a situational impact that went beyond entertainment-related aspect but contributed on a deeper and more emotional level. These situational impacts strongly correspond to the travel motivations of meeting new people and experiencing foreign cultures. Especially single longterm travellers benefitted to a greater extent from these interactions, as these contacts reduce 
the loneliness that can occur when travelling alone and fulfil a basic need for social contact thus making sociability and the motivation to meet people not only a desire but a necessity.

'We got along so well, we had so much in common, I mean, otherwise we wouldn't have spent so much time together. It's much more fun if you can do things together, you see more, you laugh more, you enjoy it more, and what's also important is that you get some kind of stability I guess. Like friends at home. Because usually, you meet people one day and the next they're gone. And it gets tiring.'

Female, Netherlands

Sharing experiences and gaining insight into the perspectives and lives of travellers from different countries and backgrounds then contributes to their desire to expand their horizons and explore foreign cultures. Although the cultures in question are not those of their destination or host community, backpacker interactions nevertheless serve as a mean to fulfil this particular motivation.

'It's just really cool that everyone I meet here is from someplace else and has been all over the world. Hearing their stories, it's so interesting, and it's kind of like taking a trip within a trip when I talk to them.'

Female, USA

\section{Impacts on the overall experience in New Zealand}

Not all social interactions with other travellers have been reported to have an impact on how the current situation was experienced, and shorter and less personal conversations especially were often said to not to leave an impression. Although backpackers tend to interact on a 
more personal level and sometimes select interaction partners based on their potential as a possible travel partner, a large number of the interactions that respondents experienced with other travellers did not necessarily contribute to fulfilling their overarching travel motivations of sociability and exposure to other cultures. In fact, a number of respondents expressed a growing dislike of the required 'backpacker talk' as their travels proceeded.

'But also, the thing is, if you come together in a hostel say, generally nine times out of ten you'll have a surface level conversation where it's about where you're from, what do you do over there, what brings you to New Zealand, how long are you here for, where have you been so far, what are you doing next, and that's kind of it. Yeah, and it gets kind of tiring sometimes. I think that you can meet kindred spirits and, ahm, really significant people in that journey, you just have to be willing to go through the other nine conversations to find the one that really makes a difference. And the longer you travel for, the harder this gets.'

Female, Australia

Although many backpacker interactions were not perceived as particularly meaningful or influential on their own, their contribution to the backpacker experience emerges when looking at the impact these have on the overall holiday. Even these short and often superficially perceived interactions nearly always included an exchange about travels in New Zealand. Backpackers especially have been found to place a high value on word of mouth recommendations (Murphy, 2001), and even if interactions did not impact the current situation or contributed on an intrinsic level, they often did impact the experience in more practical ways. 
'I talked to them for about ten minutes, and even if you don't do more stuff together, they have an impact on what else you do. It doesn't matter how short they are, if they're so enthusiastic about something then I'm like, oh yeah, I'll do that. And that makes my holiday something different.'

Female, Netherlands

Similar to situational impacts, the most frequently reported way in which interactions with other travellers contributed to the respondents' holiday is entertainment-related and focuses on the joy that these interactions bring to respondents, thus contributing to the fulfilment of the desire for social contacts and meeting new people. As indicated previously, these interactions contribute on an emotional level as well. Respondents travelling alone often relied on contacts with other travellers for their mental well-being. By having the majority of their interactions in accommodation settings, they were simultaneously exposed to different personalities as well as potential travel partners who shared similar expectations towards their interactions, making the process of achieving the required social contact easier. Respondents therefore heavily relied on social interactions with other visitors to re-create the stability and support that is usually provided by friends and family at home. If this support was lacking, even the actual destination or activities undertaken within can be perceived negatively.

'It's not always good in New Zealand of course. Sometimes you get homesick and those things, and if you have social contact, if you have longer contact, you can...yeah, talk about it. It makes the difficult parts easier. And we spent a week together, a week is long when travelling, so there was some kind of, yeah, social support I guess that you usually don't have but that's good to have sometimes.' 
Male, Belgium

'When I was in Rotorua (...) I felt quite homesick but couldn't really find nice people to spend the day with, and that's why I didn't like Rotorua that much.'

Female, Netherlands

In addition, Richards and Wilson (2004) as well as Binder (2004) state that learning about oneself is a crucial component of backpacker travel. Backpackers' desire for selfdevelopment has been found to be expressed through comparing one's own experiences and viewpoints to those of others and through narrating their own stories (e.g. Noy, 2004), leading to the impact of social interactions going beyond the on-site travel experience.

'At home, everybody is similar in terms of, of their, kind of perspective on the world. And so when you come travelling, you meet people from different backgrounds, and they sort of say something and you think, oh. Just taken that for granted, you know? And she was a prime example, talking to her made me see aspects of not only this trip but also my life differently, and, yeah, it's something I'll remember. For a long time I think.'

Female, UK

This knowledge already provides some initial insight into the reasons that can contribute to the lack of in-depth exchanges with the host community and the increasing popularity of backpacker enclaves that may be perceived to stand in contrast with their desire to experience foreign cultures in authentic ways - interactions with other travellers, often from countries or cultures other than that of respondents, can strongly contribute to the 
fulfilment of this particular travel motivation. Other travellers appear to provide sufficient opportunity to broaden the respondents' horizons and learn about other cultures, perspectives and ways of life. The commonalities of age, life stage and travel interests create common ground to reach a more personal interaction partner relationship, yet the individual differences provide ample opportunity to experience the desired exposure to other cultures.

\section{Contacts with the host community}

The frequent lack of contact with the host community can be traced back to the impact that social interactions with other travellers have on the overall travel experience of backpackers, especially the intrinsic impacts in terms of social support and stability. Those travelling with company are usually self-sufficient in their social needs, whereas single travellers need to rely on social interactions with others (Pearce, 2005b). Travelling for months, the permanent and reliable support system that is usually provided by friends and family does not exist. Backpackers in similar situations and with similar needs often contribute to their respective experience by functioning as a replacement for this system. Respondents referred to both the structure of their travels and the fact that locals have different social needs that are not necessarily compatible with their own to explain why they had experienced relatively little contact with locals.

'I haven't met so much New Zealanders, mostly people from abroad, so, just the hostel, people who work there, but no people from New Zealand. The people who work in hostels sometimes are backpackers too, so yeah, I haven't met many locals. And on the bus, it's often tourists too.'

Male, Canada 
'Well, on the one hand it's easier to meet other backpackers than locals, just because of where I go. And then, even if I stay somewhere for longer and find work, it's easier with backpackers because they're in the same situation, and you get to know each other very fast. With locals, I mean, they have their lives, they live here already, they have friends and they don't need me. But we, the girls that I'm with now, we kind of need each other because we don't know anyone else, you know?'

Female, Canada

The self-catered travel style of backpackers means that they usually rely on hostels and public transport, an infrastructure heavily used by fellow backpackers and less by locals or domestic travellers. The circumstances of their travel behaviour in combination with their personal need for a fast developing social support system therefore means that backpackers often put themselves less in the path of locals, with whom they would not be able to build the relationship they desire for their mental well-being. Even respondents on working holiday visas, often staying in one place for longer durations, reported that they begin to build up a network with other backpackers as opposed to one within the local community. When not being long-term hostel dwellers, they frequently flat with other backpackers in similar semipermanent situations - all of these factors contribute to a high social interaction rate with other travellers and a comparatively low interaction rate with locals.

'We're all on a working holiday visa, and we all have found jobs here and flat together. I guess we could have moved in with locals, but the thing is, we're not really staying for long and of course they want flatmates who stay longer. We hang out together, we're really close friends, and we travel together, we do weekend trips, and, yeah, when you're travelling you become friends very fast.' 
Female, UK

As mentioned previously, the emotional component especially is an important way in which interactions with other travellers contribute to the experience, and the longer an interaction continues for, the stronger is this benefit. Interactions with locals or domestic travellers on the other hand do not provide the opportunity to spend prolonged periods of time together, therefore making interactions with other travellers more beneficial to backpackers than interactions with the host community.

\section{Conclusion}

The situational features (Argyle et al., 1981) have been found to be a useful framework to analyse the social interactions of backpackers in New Zealand in more depth, and contribute a greater understanding of how the social aspect of backpacking manifests itself and how it is perceived by participants. Backpackers most frequently interact in youth hostel settings that provide them with the environmental and personal circumstances to engage in longer and more personal social interactions, preferred especially by long-term single travellers who often expressed an increasing dislike for the recurring and often superficially perceived 'backpacker talk'. This sequence of conversation topics based on the rules of their social interactions occurs frequently, as the role attached to backpacker travel is a social and extroverted one, represented by the overarching intrinsic goals based on which respondents interacted. However, these aspects are only part of what constitutes backpacker interactions, as their personality type and relationship with the interaction partner have been found to be the core determinants of the impact that these interactions have on their travel experience. While the importance of social contact in general has been emphasized by all respondents, the perceived depth as well as the duration based on likeability and commonalities determines 
whether interactions impact the experience on a more fun- and travel-related level or if they contribute on a more personal and emotional level by functioning as a social support system.

This research provides a first understanding of the need for a somewhat stable social environment amongst long-term travellers, and by doing so contributes new insight into the reasons underlying the apparent gap between expected and actual contacts with the host community. The needs and circumstances of travellers versus residents are perceived to differ strongly, and contacts with fellow backpackers are seen to be not only more convenient but also more rewarding, with personal wellbeing being more important than exposure to the host community. Although this may appear to stand in contrast with backpackers' desire to experience other cultures and broaden their horizons, the high desire for sociability of this visitor type provides sufficient opportunity to engage with other travellers that fulfil these motives.

While social interactions are indeed crucial for backpackers, this relies heavily on the circumstances in which they happen. The social aspect of this travel form is multi-layered and multi-dimensional, and on the micro level sometimes has less impact than the literature might suggest. Social interactions are not always perceived as a positive enhancement of the current situation and are not always welcome. Nevertheless, their sum is generally crucial for a positive overall travel experience, as certain activities, attractions and even destinations can be perceived negatively without positive social surroundings. The greatest impact of backpacker social interactions can thus be found in their contribution to mental well-being through providing social contact, support and stability especially for single long-term travellers, as well as broadening minds and horizons through exposure to visitors from different cultures and backgrounds. The motivation of sociability thus simultaneously contributes to the motivations of cultural experiences and self-development. While a lack of contact with the host community was previously observed especially (albeit not exclusively) 
in the so-called enclaves, New Zealand's tourism infrastructure does not provide travellers with such centres. It can thus be suggested that the backpacker subculture existent in these geographically defined areas may be as much a state of mind as a practical and spatial arrangement, and that the proposed benefits of enclaves such as recovery from unfamiliar surroundings, acclimatisation and convenience (Howard, 2007) are in need of further examination.

This research of course also raises questions about the social context of backpacking in general, especially about the place of destination culture within backpacker social interactions. Examining the phenomenon within other popular backpacker destinations such as South East Asia, where the cultural gap between travellers and host community can be regarded as larger than that between European/US travellers in New Zealand, would shed further light on the relative importance of host culture and community within backpacker travel. It has also been found that interactions with other backpackers change experiences for the better, contribute to greater enjoyment, and often determine not only the perception but also usage of sites and attractions within the destination through word of mouth. Further research is required to explore how the tourism industry can utilize these dynamics that may appear to be out of their control, especially in the light of social media and information technologies. 


\section{References}

Argyle, M., Furnham, A., \& Graham, J.A. (1981). Social situations. Cambridge: Cambridge University Press.

Ateljevic, I., \& Doorne, S. (2004). Theoretical encounters: A review of backpacker literature. In G. Richards \& J. Wilson (Eds.), The global nomad. Backpacker travel in theory and practice (pp. 60-76). Clevedon: Channel View Publications.

Binder, J. (2004). The whole point of backpacking: Anthropological perspectives on the characteristics of backpacking. In G. Richards \& J. Wilson (Eds.), The Global nomad. Backpacker travel in theory and practice. (pp. 92-108). Clevedon, UK: Channel View Publications.

Bushell, R., \& Anderson, K. (2010). A clash of cultures or definitions? Complexity and backpacker tourism in residential communities. In K. Hannam \& A. Diekmann (Eds.), Beyond backpacker tourism. Mobilities and experiences (pp. 187-202). Bristol: Channel View Publications.

Crouch, D., Aronsson, L., \& Wahlstrom, L. (2004). Tourist encounters. In S. Williams (Ed.), Tourism. Critical concepts in the social sciences (Vol. 2, pp. 278-295). London, New York: Routledge.

Gough, B., McFadden, M., \& McDonald, M. (2013). Critical social psychology (2 ${ }^{\text {nd }}$ ed.). Hampshire: Palgrave Macmillan. 
Grove, S.J., \& Fisk, R.P. (1997). The impact of other customers on service experiences: A critical incident examination of "getting along”. Journal of Retailing, 73, 63-85.

Hannam, K., \& Diekmann, A. (2010). From backpacking to flashpacking: Developments in backpacker tourism research. In K. Hannam \& A. Diekmann (Eds.), Beyond backpacker tourism. Mobilities and experiences (pp. 1-7). Bristol: Channel View Publications.

Harris, K., \& Baron, S. (2004). Consumer-to-consumer conversations in service settings. Journal of Service Research, 6, 287-303.

Heimtun, B. (2011). The group package tour and sociability: Contesting meanings. Tourism Review International, 14, 3-15.

Howard, R.W. (2007). Five backpacker tourist enclaves. International Journal of Tourism Research, 9, 73-86.

Huang, J., \& Hsu, C.H.C. (2010). The impact of customer-to-customer interaction on cruise experience and vacation satisfaction. Journal of Travel Research, 49, 79-92.

Huxley, L. (2004). Western backpackers and the global experience: An exploration of young people's interaction with local cultures. Tourism, Culture \& Communication, 5, 37-44.

Jarvis, J., \& Peel, V. (2010). Flashpacking in Fiji: Reframing the 'global nomad' in a developing destination. In K. Hannam \& A. Diekmann (Eds.), Beyond backpacker tourism: Mobilities and experiences (pp. 21-39). Bristol: Channel View Publications. 
Levy, S.E., \& Getz, D. (2012). An exploration of social stimuli influencing the student sightseeing tour experience. Tourism Review International, 15, 297-311.

Loker-Murphy, L., \& Pearce, P.L. (1995). Young budget travelers: Backpackers in Australia. Annals of Tourism Research, 22, 819-843.

Mossberg, L. (2007). A marketing approach to the tourist experience. Scandinavian Journal of Hospitality and Tourism, 7, 59-74.

Murphy, L. (2001). Exploring social interactions of backpackers. Annals of Tourism Research, 28, 50-67.

Newlands, K. (2004). Setting out on the road less travelled: A study of backpacker travel in New Zealand. In G. Richards \& J. Wilson (Eds.), The global nomad. Backpacker travel in theory and practice (pp. 217-236). Clevedon: Chanenl View Publications.

Niggel, C., \& Benson, A. (2008). Exploring the motivations of backpackers: The case of South Africa. In K. Hannam \& I. Ateljevic (Eds.), Backpacker tourism. Concepts and profiles (pp. 144-156). Clevedon: Channel View Publications.

Noy, C. (2004). This trip really changed me. Backpackers' narrative of self-change. Annals of Tourism Research, 31, 78-102. 
O'Regan, M. (2010). Backpacker hostels: Place and performance. In K. Hannam \& A. Diekmann (Eds.), Beyond backpacker tourism: Mobilities and experiences (pp. 85-101). Bristol: Channel View Publications.

O'Reilly, C.C. (2006). From drifter to gap year tourist. Mainstreaming backpacker travel. Annals of Tourism Research, 33, 998-1017.

Paris, C.M. (2012). Flashpackers: An emerging sub-culture? Annals of Tourism Research, 39, 1094-1115.

Paris, C.M., \& Teye, V. (2010). Backpacker motivations: A travel career approach. Journal of Hospitality Marketing \& Management, 19, 244-259.

Pearce, P.L. (1984). Tourist-guide interaction. Annals of Tourism Research, 11, 129-146.

Pearce, P.L. (1990). Farm tourism in New Zealand: A social situation analysis. Annals of Leisure Research, 17, 337-352.

Pearce, P.L. (2005a). The role of relationships in the tourist experience. In W.F. Theobald (Ed.), Global tourism (3 ed., pp. 103-122). Amsterdam: Elsevier.

Pearce, P.L. (2005b). Tourist behaviour. Themes and conceptual schemes. (Vol. 27). Clevedon: Channel View Publications. 
Richards, G., \& Wilson, J. (2004). Drifting towards the global nomad. In G. Richards \& J. Wilson (Eds.), The global nomad. Backpacker travel in theory and practice (pp. 3-13). Clevedon: Channel View Publications.

Riley, P.J. (1988). Road culture of international long-term budget travelers. Annals of Tourism Research, 15, 313-328.

Ryan, C. (2010). Ways of conceptualizing the tourist experience. A review of literature. Tourism Recreation Research, 35, 37-46.

Scheyvens, R. (2002). Backpacker tourism and third world development. Annals of Tourism Research, 29, 144-164.

Tourism New Zealand. (2013a). Visitor experience monitor - youth Retrieved 17/09/2013, from http://www.tourismnewzealand.com/sector-marketing/youth-market/visitor-experiencemonitor-survey/

Tourism New Zealand. (2013b). The youth market Retrieved 17/09/2013, from http://www.tourismnewzealand.com/sector-marketing/youth-market/

Tucker, H. (2005). Narratives of place and self: Differing experiences of package coach tours in New Zealand. Tourist Studies, 5, 267-282. 
Vance, P. (2004). Backpacker transport choice: A conceptual framework applied to New Zealand. In G. Richards \& J. Wilson (Eds.), The global nomad. Backpacker travel in theory and practice (pp. 237-250). Clevedon: Channel View Publications.

Walls, A.R., \& Wang, Y. (2011). Experiential consumption and destination marketing. In Y. Wang \& A. Pizam (Eds.), Destination marketing and management. Theories and applications (pp. 82-98). Wallingford: CABI.

Wilson, J., \& Richards, G. (2008). Suspending reality: An exploration of enclaves and the backpacker experience. In K. Hannam \& I. Ateljevic (Eds.), Backpacker tourism. Concepts and profiles (pp. 9-25). Clevedon: Channel View Publications.

Wilson, J., Richards, G., \& MacDonnell, I. (2008). Intracommunity tensions in backpacker enclaves: Sydney's Bondi beach. In K. Hannam \& I. Ateljevic (Eds.), Backpacker tourism. Concepts and profiles (pp. 199-214). Clevedon: Channel View Publications.

$\mathrm{Wu}$, C.H.-J. (2007). The impact of customer-to-customer interaction and customer homogeneity on customer satisfaction in tourism service - the service encounter prospective. Tourism Management, 28, 1518-1528. 
Table 1

Enhanced features of social situations (adapted from Pearce, 1990, p. 342)

\section{Original Feature}

Roles

Environmental setting

Goals

Repertoire of elements (behaviours)

Sequences

Rules

Concepts and cognitive structure

Language and speech

\section{Brief definition}

Roles are the duties or obligations which attend the social positions people occupy.

Environmental setting consists of the props, spaces, barriers, modifiers which influence the situation.

Goals may be seen as the purpose or ends which direct social behaviour.

The sum of behaviours which are appropriate to that situation.

The ordering of the repertoire of behaviours. Sequences may be very fixed or very fluid.

Rules are the shared beliefs which regulate behaviour.

Concepts and cognitive structures may be thought of as the shared definitions and understandings needed to operate in the social situations.

How things are said, the code of speech, vocabulary, and social variation inherent in language.

\begin{tabular}{ll}
\hline Additional Feature & Brief definition \\
\hline Personality type & $\begin{array}{l}\text { Sociability and importance placed upon social interactions } \\
\text { with other travellers. }\end{array}$ \\
$\begin{array}{l}\text { Interaction partner } \\
\text { relationship }\end{array}$ & $\begin{array}{l}\text { Determined by mutual likeability, commonalities or their } \\
\text { absence. }\end{array}$ \\
\hline
\end{tabular}


Table 2

Sample characteristics based on 37 interviews with backpackers

\section{Frequency}

Percentage

Gender

Female

26

70.3

Male

11

29.7

Age Group

$18-29$ years

30

81.1

$30-39$ years

5

13.5

$40-49$ years

2

5.4

Area of Origin

Europe 32

86.5

USA/Canada

4

10.8

Australia/Oceania

1

2.7

Length of Stay

Less than one month

5

One to six months

21

13.5

Six months to one year

11

56.8

29.7

Group constellation

Single

30

81.1

Friends/Partner

7

18.9

Preferred transport mode

Public bus networks

12

32.4

Backpacker bus networks

11

29.7

Rental car/campervan

10

27.1

Other

4

10.8

Preferred accommodation type

Youth Hostels

36

97.3

Campsites

1

2.7 